\title{
Un análisis lingüístico sobre las características del lenguaje jurídico italiano y español
}

\author{
A linguistic analysis of the characteristics of Italian and Spanish legal language \\ Rubén González Vallejo ${ }^{1}$ - (1) https://orcid.org/0000-0002-9697-6942 \\ Università degli studi di Macerata \\ Corso Cavour, 2 - Università degli Studi di Macerata 62100 Macerata (MC, Italia)
}

\section{RESUMEN}

El lenguaje jurídico se concibe como una subvariedad de la lengua común caracterizada por rasgos muy concretos y se muestra como el reflejo inmutable de los comportamientos que subyacen en cada cultura y que la diferencian de otras. A tal propósito, el presente artículo se propone recoger las particularidades esenciales del lenguaje jurídico italiano y español para tener en cuenta en su análisis por parte de juristas y profesionales de la lengua, todo ello a través de numerosos ejemplos extraídos de la legislación vigente.

Inicialmente se abordará el plano léxico-semántico, en donde la presencia de palabras extranjeras y la fraseología acapararán el principal protagonismo; el nivel morfosintáctico, por su parte, prestará especial atención a la nominalización y a los tiempos verbales usados en ambos idiomas; por último, el nivel ortográfico y estilo se centrará principalmente en el uso de siglas y abreviaturas y en el oscurantismo del lenguaje jurídico.

Palabras clave: Derecho, lenguaje jurídico, lenguaje de especialidad, morfología, extranjerismos

\section{Abstract}

Legal language is conceived as a sub-variety of the common language characterized by very specific features and is shown to be the immutable reflection of the behaviors that underlie each culture and differentiate it from others. In this regard, this article brings together the particularities of Italian and Spanish legal language in order to provide a brief decalogue of the most representative aspects to be taken into account in its translation through numerous examples drawn from current legislation.

Initially, the lexical-semantic level will be dealt with, where the presence of foreign words and phraseology will take the main role; the morphosyntactic level, on the other hand, will pay special attention to the nominalization and the verbal tenses used in both languages; and finally, the orthographic and style level will focus mainly on the use of acronyms and abbreviations and on the obscurantism of legal language.

Keywords: Law, legal language, speciality language, morphology, foreign languages

\section{El lenguaje jurídico como lengua del derecho}

El lenguaje jurídico se enmarca en los lenguajes de especialidad o sectoriales ya que los factores socioculturales y temáticos son relevantes en el intercambio comunicativo (Rodríguez, 1981). Dichas temáticas no solamente recogen los aspectos específicos de las ramas del derecho, sino todas las realidades que puedan tener cabida en su objetivo de controlar el orden en la comunidad (en un juicio sobre negligencia médica, la jerga usada no será 
baladí). La confluencia con la lengua común es fuerte hasta el punto de considerarse una subvariedad de la misma y producirse transvases lingüísticos continuos: palabras del derecho han pasado al vulgo, como 'coartada' y 'amnistía', y viceversa, como los neologismos burning o moobing.

Algunos autores subrayan que la lengua común se encuentra en la base de la comunicación especializada (Belvedere, 2016; Gotti, 1991), pero el lenguaje jurídico carece de las mismas variaciones lingüísticas, ya que al ser una subvariedad se entiende como una rama específica con características propias. De hecho, la interpretación del lenguaje jurídico en ocasiones no es inmediata para el hablante no docto, debiendo afrontar giros oscuros y repetitivos y una sintaxis cuando menos enrevesada. Esto representa un escollo en la comunicación, pues si bien el destinatario inmediato es el jurista, el destinatario final de las leyes es el ciudadano, el cual requiere de una mediación lingüística para la comprensión del texto. Si bien haya en marcha proyectos sobre normas de redacción para la mejora de la sintaxis legislativa, es inevitable observar que lengua y variante se comportan de manera diferente, pudiéndose llegar a reconocer una denotación semántica más precisa en el lenguaje jurídico y a nivel estructural una extensión considerable de los periodos. Por todo ello, y dejando a un lado la afamada equivalencia plena de los términos jurídicos debido a los factores socioculturales que subyacen en ambos ordenamientos, nos proponemos en el siguiente apartado desglosar las características esenciales del lenguaje jurídico italiano y español con el fin de otorgar una píldora formativa a juristas y profesionales de la lengua en su cometido de redacción y traslación.

\section{Características del lenguaje jurídico}

Esta sección tiene como objetivo ilustrar las principales características del español e italiano jurídicos en función de lo recogido por la literatura de especialidad, pues su estudio facilitará el análisis del microtexto. Para ello, se llevará a cabo un análisis a partir de tres planos. Inicialmente, en el plano léxico-semántico tendrán lugar los extranjerismos que subyacen en la formación de palabras de la lengua del derecho junto a fenómenos como la metáfora y el eufemismo. Posteriormente, en el plano morfosintáctico tendrá cabida principalmente la nominalización y la morfología verbal, por ser dos componentes de elevada recurrencia en el lenguaje jurídico. Por último, en el plano ortográfico y estilo se analizarán las siglas y las abreviaturas, las elipsis y se reflexionará sobre el oscurantismo del lenguaje jurídico.

Para otorgar un mayor rigor científico a lo expuesto, los numerosos ejemplos serán extraídos del Código penal y civil italiano y español y de los buscadores legislativos BOE y Normattiva.

\subsection{Nivel léxico-semántico}

\subsubsection{Presencia de palabras extranjeras}

El lenguaje jurídico recurre con frecuencia a extranjerismos, pues recoge la esencia de la evolución social de un país y bien es sabido que la historia está hecha de pueblos invasores. Por ello, el presente apartado está a dirigido a detectar la base de las palabras que conforman el lenguaje jurídico. De entre todos los idiomas, nos centraremos en el latín, el griego, el árabe, el inglés, el francés y el alemán por la importancia que han recubierto en ambos países. 


\subsubsection{Latinismos}

El uso de latinismos es recurrente en ambos idiomas como expresión de la evolución del nacimiento de las lenguas románicas a través del latín vulgar. Sin embargo, es inevitable no reconocer un prestigioso aumento de ellos en italiano, fruto de la interacción del latín con el italiano que apareció en el Trecento, pues como bien indica Gualdo (2011), "latino e volgare si contaminano e il passaggio dall'una all'altra è sfumato" (p. 433). En el lenguaje jurídico regalan una nota grandilocuente y ampulosa a la frase y cabe notar la adaptación de muchos de estos términos en español, como 'cuórum' por quorum o 'currículo' por curriculum frente al hermetismo italiano, que prefiere los llamados latinismos crudos.

$$
\begin{aligned}
& \text { [...] se aplicará a las demandas de exequátur que se presenten ante los órganos jurisdiccionales } \\
& \text { españoles [...]. (art. } 8 \text { Resolución BOE, 2020) } \\
& \text { [...] la cui osservanza è obbligatoria, iure o facto, per la commercializzazione, la prestazione di } \\
& \text { servizi, [...]. (art. 1.f) GU núm. 233, 2017) }
\end{aligned}
$$

\subsubsection{Helenismos}

Componen la segunda fuente de riqueza terminológica después del latín. Los encontramos a través de muchos prefijos y sufijos como -auto o -logia y -logo (Vucetic, 2015), pero también «latinizados en latín tardío y medieval» (Frago, 1980,p. 396) o a través del francés como en el caso de 'anarquista' (anarchiste), o del inglés con 'amnistía' (amnesty).

2. ${ }^{\circ}$ El crédito de la partida presupuestaria JU 01 D/480.0012/131, «Indemnizaciones personas incluidas supuestos Ley 46/77, de concesión de amnistía». (art 10. 2. BOE 4/2020)

12-quater. I finanziamenti di cui al comma 12 del presente articolo sono garantiti da ipoteca di primo grado su immobili residenziali. (art. 1. 1. BOE núm. 44, 2015)

\subsubsection{Arabismos}

El fervor de la Guerra Santa llegó al norte de África pasando posteriormente a la península y a Sicilia. La administración árabe y las leyes dejaron inevitablemente más huella en la Península, en donde permanecieron desde el 711, año en el que ganaron la Batalla de Guadalate contra el último rey visigodo Rodrigo, hasta 1492 cuando fueron expulsados por los reyes católicos del Reino Nazarí de Granada (Lapesa, 1981). Fruto de esto, en español podemos encontrar el arabismo a través de una transliteración o por medio de cambios fonológicos y morfológicos (Millar, 1998), como en 'alevosía' o 'alcalde'. En italiano, por su parte, los arabismos se pueden encontrar en Sicilia en términos jurídicos como albaranau, que significa 'escritura privada' o cangemia, ‘impuesto de los bárbaros', entre otros (Mancini, 2010).

«1. Será castigado con la pena de prisión de quince a veinticinco años, como reo de asesinato, el que matare a otro concurriendo alguna de las circunstancias siguientes: 1. ${ }^{a}$ Con alevosía. (art. 76, BOE 1/2015)

2. La categoria degli ufficiali comprende: a) ufficiali generali
gradi di generale di brigata, [...]. (art. 1.2. GU núm. 94 2017)

\subsubsection{Anglicismos}

Los anglicismos realizan su aparición significativamente a finales del s. XX en el campo científico y tecnológico. Se suele distinguir entre anglicismo necesario, por el cual un término no encuentra una respuesta en la lengua 
de llegada como camping, y superfluo, cuyo uso se aleja del lingüístico perteneciendo al "dominio de la comunicación inferencial". Es cuando menos relevante la adopción de anglicismos sin adaptar en italiano con términos como Plastic tax o Jobs act para designar leyes (que traduciríamos como 'tassa sulla plastica' y 'riforma del lavoro', respectivamente), factoring, leasing, soft law, impeachment (en español encuentra respuesta en 'proceso por destitución') antitrust ('derecho de la competencia') y Welfare para referirse al Ministerio de trabajo y políticas sociales. Por otra parte, un caso de gran riqueza terminológica lo representa el paso de palabras provenientes de la lengua común y de otros sectores que han entrado en el campo jurídico (piénsese en los casos de stalking, moobing y grooming).

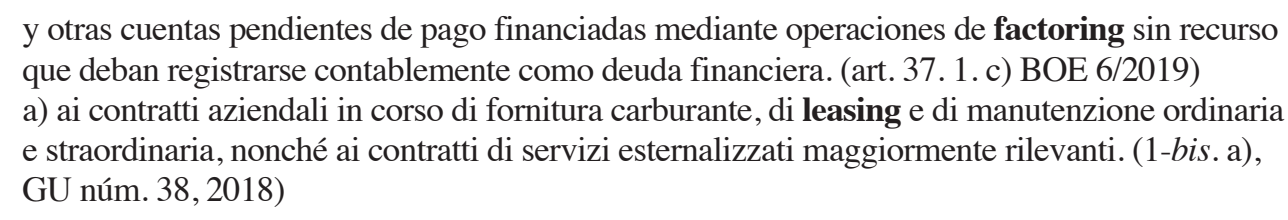

\subsubsection{Galicismos}

Entran a finales del 800 a través del Código Napoleónico y regalan un gran abanico terminológico a ambos países. Algunos ejemplos en español son 'chantaje' (chantage) o 'requisa' (réquisition) y en italiano bancarotta (banqueroute') o reclusione (réclusion). Para Caterina Rossi (2008), en Italia los galicismos aportan diversos nombres que encontramos en las actuales instituciones, como Corte di Cassazione, Consiglio di Stato o procedura civile.

$$
\begin{aligned}
& \text { Cuando la requisa se acuerde de oficio, se informará previamente a la Administración } \\
& \text { autonómica o local correspondiente. (art. 8.1 BOE 463/2020) } \\
& \text { 8. All'articolo } 342 \text { del codice penale è premesso il seguente: Art. 341-bis. - (Oltraggio a } \\
& \text { pubblico ufficiale). (art. 1.8. GU núm. 94, 2009) }
\end{aligned}
$$

\subsubsection{Germanismos}

Contrariamente al pensamiento común, con germanismos nos referimos no solo a los términos alemanes, sino a los provenientes de las lenguas germánicas (Corbacho, 2004). Ejemplos de ellos en español encontramos 'cameralismo' (kammer) y 'consorcio' (konzern). En Italia, Caterina Rossi (2008) reflexiona sobre la entrada de nociones jurídicas alemanas que el francés desconocía, como el caso de fattispecie (tatbestand) o rapporto giuridico (rechtsverhältnis).

$$
\begin{aligned}
& \text { 6. Descripción de la licitación: Adquisición de repuestos y herramientas obús 155/52 y V07. } \\
& \text { (ap. 6. BOE núm. 78, 2020) } \\
& \text { all'articolo 11, comma 1, le parole «Il Corpo delle capitanerie di porto - Guardia costiera } \\
& \text { dipende». (art. 1. 1. h) GU núm. 138, 2019) }
\end{aligned}
$$

\subsubsection{Italianismos/hispanismos}

El desembarco en el Reino de Sicilia y Nápoles se realiza por las conquistas de Ceriñola y Garellano en 1503 (Luciano, 2014), lo cual provocó un influjo de hispanismos en el Bel Paese. Fruto de ello, además de diversas palabras relacionadas con la navegación, en napoletano encontramos palabras como «appoderato 'procuratore', continuo ‘valletto, paggio', arbarano 'scrittura privata, strumento' [...]» (Riccio, 2005, p. 3). 
En España, el influjo italiano se dejó sentir irremisiblemente en el campo de la música y del arte en los s. XV y XVI. En el lenguaje jurídico encontramos 'libreto', 'libelo’ y ‘póliza', entre muchos otros

$$
\begin{aligned}
& \text { que se ocupe de materias tales como el mantenimiento del orden público, daño público, asalto, } \\
& \text { tumulto, libelo criminal, conspiración y atentados. (ap. } 2 \text { Resolución BOE, 1982) } \\
& \text { e verifiche per accertare la permanenza dei requisiti di cui al comma } 2 \text { e il regolare e } \\
& \text { svolgimento delle procedure previste dal regolamento DPI. (art. 1. 1. f) DL GU núm. 17, 2019) }
\end{aligned}
$$

\subsubsection{Fraseología especializada: los binomios y multinomios}

La fraseología recubre no solo un plano superficial, formando parte de la conversación cotidiana, sino también un nivel más profundo en el campo de la lingüística aplicada con disciplinas como la enseñanza de segundas lenguas (Quiroga, 2006). Las colocaciones y las unidades fraseológicas se presentan como esquemas estables compuestos por al menos dos unidades léxicas (Corpas, 1998; Sciutto, 2005) y la ampulosidad y la altisonancia se dejan ver en el lenguaje jurídico a través de fórmulas cristalizadas que carecen de contenido informacional, como los casos de 'en virtud de' y 'a tenor de lo expuesto' en español y 'ai sensi di' y 'resto fermando' en italiano, entre muchos otros. Kjaer (2007) ha estudiado la fraseología en el lenguaje jurídico recreando 5 categorías específicas que a continuación mostramos con ejemplos extraídos del código civil español (CC) e italiano $(\mathrm{CCI})$.

\begin{tabular}{ll}
\hline Términos poliléxicos & Medida cautelar (art. 339 CP), representante legal (art. 147. IV CP) \\
\hline Colocaciones & Dictar sentencia (art. 119. CP) \\
\hline Construcciones con verbo soporte & Imponer una multa (art. 52. II CP \\
\hline Binomios & Cargas y obligaciones (art. 986 CC) \\
\hline Frasemas jurídicos & De oficio (art. 58. II CP)
\end{tabular}

Tabla 1. La fraseología según Kjaer (2007)

Un caso emblemático es el de la variación geográfica de la terminología y es que compartir una lengua no implica compartir una cultura, como en el caso de los países que conforman el espectro Hispanoamérica, en donde podemos encontrar para la misma colocaciones soluciones como 'tentativa de delito' (España), 'estado de tentativa' (Costa Rica) y 'en grado de tentativa' (Paraguay). Otros casos evidenciados en anteriores trabajos (González Vallejo, 2020) serían la equivalencia del término Codice di procedura penale, que en España sería 'Ley de Enjuiciamiento criminal' mientras que en países como Colombia o Ecuador se usaría 'Código de Procedimiento Penal' y en Guatemala y Honduras 'Código Procesal Penal', y Corte di Appello, que en España se correspondería parcialmente con la Audiencia Nacional mientras que encuentra respuesta en países como Chile y Guatemala en ‘Corte de Apelación’.

Un caso específico y de gran relevancia es el de los binomios y multinomios que Malkiel (1959) clasifica como secuencias que pertenecen a la misma categoría y al mismo nivel semántico unidas a través de un conector. Estos elementos de cierto aspecto retórico suponen un gran reto traductor en la búsqueda de la correspondencia formal en el otro ordenamiento jurídico. A continuación, presentamos los tipos de binomios/ multinomios que podemos encontrar extraídos del código civil y penal español (CC/ CP) e italiano (CCI/ CPI).

\begin{tabular}{lll}
\hline & Español & Italiano \\
\hline Sustantivo & $\begin{array}{l}\text { Riesgo e incumplimientos (art. 31 bis), } \\
\text { atenuantes y agravantes (art. 66 CP), }\end{array}$ & $\begin{array}{l}\text { Termini e forme (art. 38 CPI), affari e interessi } \\
(\text { art. 343 CCI) }\end{array}$ \\
\hline
\end{tabular}




\begin{tabular}{|c|c|c|}
\hline Verbo & $\begin{array}{l}\text { Pública e indebidamente (art. } 402 \text { bis CP), } \\
\text { derogar, suspender o modificar (art. } 472 \mathrm{CP} \text { ) }\end{array}$ & $\begin{array}{l}\text { Dichara o attesta (art. } 374 \text { bis CPI), chiunque } \\
\text { sottrae, sopprime, distrugge, disperde o deteriora } \\
\text { (art. } 334 \mathrm{CPI} \text { ) }\end{array}$ \\
\hline Adjetivo & $\begin{array}{l}\text { Relevante y favorable (art. } 90 \mathrm{CP} \text { ), étnico, } \\
\text { cultural o religioso (art. } 170 \mathrm{CC} \text { ) }\end{array}$ & Nucleare, chimico o biologico (art. $375 \mathrm{CPI}$ ) \\
\hline Adverbio & $\begin{array}{l}\text { Total o parcialmente (art. } 301 \mathrm{CP} \text { ), válida, } \\
\text { libre, espontánea y expresamente (art. } 155 \\
\text { CC) }\end{array}$ & $\begin{array}{l}\text { Espressamente o tacitamente (art. } 155 \mathrm{CPI} \text { ), } \\
\text { congiuntamente o alternativamente (art. } 157 \mathrm{CPI})\end{array}$ \\
\hline Preposición & $\begin{array}{l}\text { En todo o en parte (art. } 472 \mathrm{CP}) \text {, por sí o por } \\
\text { otro (art. } 360 \mathrm{CC})\end{array}$ & $\begin{array}{l}\text { Con dolo o con colpa (art. } 2600 \mathrm{CCI}) \text {, con } \\
\text { violenza, minaccia o suggestione (art. } 579 \mathrm{CPI})\end{array}$ \\
\hline
\end{tabular}

Tabla 2. Binomios y multinomios en el español e italiano jurídicos

\subsubsection{Formación terminológica}

En el lenguaje jurídico, los sufijos dominan el panorama en los mecanismos de formación seguidos de la composición. En los sufijos españoles encontramos un predominio por parte de los latinizados -al ('patrimonial', 'constitucional') -miento ('cumplimiento', 'arrendamiento') -ante ('causante', 'representante') -anza ('llevanza', 'fianza') y -atario ('donatario', 'legatario'). En el caso italiano, en cambio, encontramos -anza ('istanza', 'rappresentanza'), -enza ('sentenza', 'delinquenza') -monio ('matrimonio', 'patrimonio'), -ale ('giudiziale', 'costituzionale') -ario ('cessionario', ‘usuffrutuario'), -abile ('imputabile', 'responsabile') e -ibile ('suscettibile', 'divisibile') (Fiorelli, citado en Gualdo y Telve, 2011).

(15) Los donatarios, los legatarios que no lo sean de parte alícuota [...] no podrán pedir la reducción ni aprovecharse de ella. (art. $655 \mathrm{CC}$ )

(16) Le stesse disposizioni si applicano anche nei confronti dell'usufruttuario e dell'affittuario [...]. (art. $2559 \mathrm{CCI})$

\subsubsection{Elipsis}

La elipsis realiza su aparición en el lenguaje jurídico con carácter anafórico sustituyendo un segmento cuyo contenido se puede recuperar por el contexto» (DRAE, 2014). En el lenguaje de la ley, la elipsis nominal es el mecanismo anafórico más frecuente en ambos idiomas, fruto en la mayoría de las ocasiones de la necesidad de recoger el elemento al que se ha hecho referencia y que, a causa de la elevada hipotaxis presente en el texto, se encuentra alejado peligrando de convertirse en un anacoluto. En español encontramos algunos anafóricos como 'mencionado', 'dicho', 'citado', 'tal', 'susodicho', 'indicado', 'aludido', 'mismo' y en italiano, citato, sopraccitato, suddetto, sopraelencato, stesso, medesimo, entre muchos otros.

(17) para los ejemplos de la parte española que al respecto fueron presentadas por los gestores de red a lo largo de 2018 y las conclusiones de los grupos de trabajo, anteriormente mencionados. (ap. 2. BOE 647/2020)

(18) [...] purché, entro sei mesi dalla suddetta comunicazione, presentino domanda di autorizzazione secondo le norme previste dal presente decreto;». (art. 1.4. GU núm. 165, 2019)

\subsubsection{Metáfora y eufemismo}

La metáfora se presenta como la proyección de un concepto físico a partir de las ideas con las que el hablante concibe la realidad (Vergara y Mansilla, 2017). El lenguaje jurídico, si bien estigmatizado como rígido y estereotipado, da también muestras de ella, como en el art. 131.3 de la Ley 11/2019 que habla de «rama 
económica» y el DL n. 307 de 2003, que menciona los «rami diversi dall'assicurazione sulla vita». En ocasiones, se recurre a la metáfora para eclipsar una realidad no aceptada socialmente, dando lugar al eufemismo. De hecho, no es inusual escuchar «crecimiento negativo» cuando el término más utilizado es «recesión»o, como indica el art. 1.7. a) del Reglamento CE núm. 2698/2000, «reforma económica» en vez de recortes.

\subsection{Nivel morfosintáctico}

\subsubsection{Nominalización}

Este mecanismo constituye un proceso recurrente de adaptación nominal de verbos o adjetivos a través de sufijos como -miento (-mento), -ción (-zione) o -atura (-atura), entre otros, en el lenguaje jurídico. Su uso permite, al igual que la voz pasiva, esconder el sujeto de la acción.

(19) [...] correspondiendo decidir en todo caso sobre su inculpación, prisión, procesamiento y juicio al Tribunal Superior de Justicia de la Comunidad Autónoma [...]. (art. 26.2 BOE 7/1981)

(20) A tal fine, andrà disposto il contestuale versamento delle dette disponibilità in conto entrata al bilancio, [...]. (art. 2.p) GU núm. 116)

Como ejemplo de readaptación, ponemos de manifiesto que el último ejemplo se podría también redactar de la siguiente manera «A tal fine, verranno versate le dette disponibilità in conto entrata al bilancio [...]».

\subsubsection{Morfología verbal}

Es la morfología verbal quizá entre el español y el italiano uno de los puntos focales más importantes para tener en cuenta en la traducción. El español jurídico muestra una clara tendencia hacia el tiempo futuro y el modo de subjuntivo, pues el matiz de probabilidad que otorga se prefiere frente a la concreción. El futuro de subjuntivo representa una posición lingüística arcaica que actualmente todavía deja huella, pese a las críticas que recibe por no mostrar un lenguaje cercano: perdió fuerza en la literatura y esto le supuso un fuerte desclasamiento en la morfología verbal española (Martínez, 1997), sobreviviendo como característica arcaica del lenguaje de la ley. No sin razón, se nos presentan inusuales las formas «se decidiere»o «se hubiere tramitado», pues su uso en el lenguaje común no encuentra correspondencia. De hecho, las formas del futuro de subjuntivo encuentran respuesta en el modo indicativo: la forma simple «se decidiere» se puede sustituir por «se decida» como por ejemplo en la frase «cuando se decidiere (decida) elevar la pena al reo a diez años, [...]»; por su parte, la forma compuesta «cuando se hubiere decidido» la encontramos junto al pretérito compuesto del subjuntivo «se haya decidido» como por ejemplo en la frase «cuando se hubiere decidido (haya decidido) elevar la pena al reo a diez años, $[\ldots] \gg$. Su uso se justifica en el efecto ampuloso y solemne que busca el lenguaje jurídico otorgando un grado remoto de realización de la acción y suponiendo un claro distanciamiento por parte del legislador (Edelmann, 2012).

Por su parte, el italiano favorece la aparición del presente de indicativo al ser un tiempo que expresa eficazmente la percepción jurídica frente al uso del futuro y del subjuntivo, recurriendo a estos en menor proporción con gran probabilidad por parte del legislador de otorgar una homogeneidad al texto.

(21) Denegación administrativa de las solicitudes formuladas por el extranjero para continuar permaneciendo en territorio español, salvo que la solicitud se hubiere realizado al amparo del 
artículo 29.3. (art. 26.3.c) BOE 4/2000).

Il Governo è delegato a emanare, entro il termine di sei mesi dalla data di entrata in vigore della presente legge [...]. (art. 1. 1. GU núm. 433, 1997)

Los participios son recurrentes en ambos idiomas, si bien en italiano se cuentan más participios presentes, incluso en la lengua común, y un participio absoluto más recurrente. En cuanto a los primeros, encontramos formas como irriverente, recante o abbiente; mientras que los segundos están representados por frases como «cumplidos los plazos»o «sentite le parti» y se usa por la economía que suponen al no mantener un vínculo gramatical con la frase.

Excepcionalmente, cumplidas las circunstancias $1 .{ }^{\mathrm{a}}$ y 3 . $^{\mathrm{a}}$ del apartado 1 del artículo anterior, el Juez de Vigilancia Penitenciaria [...]. (art. 91 CP)

Il decreto-legge 10 maggio 2020, n.30, recante misure urgenti in materia di studi [...]. (art. 1.

1, GU núm. 72, 2020)

El gerundio es una de las cuestiones sin resolver en la redacción legislativa, puesto que se siguen localizando usos incorrectos e indebidos que parecen provenir del derecho francés (Alcaraz, 2002). Este autor recoge los 5 casos más comunes de la manifestación del gerundio en textos legales:

1. La construcción estar seguida de gerundio, como en «el juez está dictando sentencia»;

2. El gerundio que expresa simultaneidad y que se corresponde con la acción principal, como en «lo homologará siguiendo el procedimiento extraordinario»;

3. El famoso e incorrecto gerundio de posterioridad en frases como «El juez resolverá oyendo»;

4. El gerundio con función adjetiva como el afamado gerundio del BOE en frases como «decreto reformando...» en vez de introducir el relativo que, como en «que reforma»;

5. La concatenación de gerundios dificulta la interpretación de los textos debido a las numerosas funciones de este modo.

La voz pasiva es otro de los escollos en la contrastiva entre el español y el italiano por la asimetría que recubre. Si bien se usa para enfatizar el sujeto, a veces se recurre a ella por obligación al no existir el mismo. Encontramos en ambos idiomas una distribución funcional diversa, pues en italiano este uso recurrente de la voz pasiva encontraría respuesta en el deseo de subrayar el complemento directo mientras que en español se tiende a evitar su uso, sobre todo en su forma perifrástica, siendo relegada a registros lingüísticos más elevados (Nuñez, 2009). Asimismo, su uso se justifica en la preferencia por los hechos atemporales y en la decisión de ocultar el emisor a través de los giros impersonales que otorgan el llamado si passivante en italiano y la impersonal refleja y la pasiva refleja en español, siendo esta última la más frecuente en textos legales.

(25) En ningún caso se podrán sustituir penas que sean sustitutivas de otras. (art. 88.4 CP)

(26) Se si tratta di leggi eccezionali o temporanee, non si applicano le disposizioni dei capoversi precedenti. (art. 2.5 CPI)

Por último, cabe destacar el papel que recubre el tiempo condicional en el italiano jurídico y que Mortara Garavelli (2001) clasifica en los siguientes tres casos que extraemos del Código penal italiano: con condición implícita en frases dependientes como en «quando la condanna importerebbe, secondo la legge italiana, una pena accessoria» (art. 12. I. 2); con prótasis explícita como en «si applica la pena che sarebbe inflitta se non concorresse alcuna di dette circostanze» (art. 69. III) y con condición de irrealidad o imposibilidad como en «la 
punibilità è esclusa se il fatto è commesso da chi per legge non avrebbe dovuto essere richiesto di fornire informazioni ai fini delle indagini» (art. 384. II).

\subsubsection{Relaciones parataxis-hipotaxis}

Inicialmente la coordinación y yuxtaposición de las frases, conocida como parataxis, surge por la inmadurez cultural y literaria de los pueblos (Prieto, 1959). Con el tiempo evolucionó adquiriendo esquemas subordinantes al detectar los hablantes cognitivamente sólidas asociaciones entre las frases, lo cual dio lugar a la hipotaxis. Para Alcaraz (2002) el lenguaje jurídico es hipotáctico mientras que el científico-técnico es paratáctico. El español y el italiano jurídicos dan muestra de ambas estructuras, predominando las relaciones hipotácticas al concebirse como un elemento grandilocuente y de precisión por parte del legislador.

$$
\begin{aligned}
& \text { Los Jueces o Tribunales podrán sustituir, [...], antes de dar inicio a su ejecución, las penas de } \\
& \text { prisión que no excedan de un año por arresto de fin de semana o multa, aunque la Ley no } \\
& \text { prevea estas penas para el delito de que se trate, cuando las circunstancias personales del reo, } \\
& \text { [...], siempre que no se trate de reos habituales. (art. } 88.1 \mathrm{CP} \text { ) } \\
& \text { Nel caso di giuramento deferito d'ufficio, il colpevole non è punibile, se ritratta il falso prima } \\
& \text { che sulla domanda giudiziale sia pronunciata sentenza definitiva, anche se non irrevocabile. } \\
& \text { (art. } 371.2 \mathrm{CPI} \text { ) }
\end{aligned}
$$

\subsubsection{Adverbios en mente}

En los adverbios que acaban en -mente encontramos una ligera asimetría en su composición, pues cuando se concatenan dos o más, el español contrae el primer adverbio, mientras que el italiano deja invariable cada una de sus formas.

$$
\begin{aligned}
& \text { Aumentar deliberada e inhumanamente el sufrimiento de la víctima, causando a ésta } \\
& \text { padecimientos innecesarios para la ejecución del delito. (art. 22. } 5 \mathrm{CP} \text { ) } \\
& \text { Chiunque pubblicamente e intenzionalmente distrugge (art. 404. 2. CPI) }
\end{aligned}
$$

\subsubsection{Anacolutos}

El anacoluto se presenta como una incongruencia y falta de cohesión entre las partes de la frase. No es raro encontrar en español sentencias que presentan anacolutos tras el encabezamiento de apertura o de fallo, como en el siguiente ejemplo:

Visto en juicio oral y público ante la Sección Séptima de esta Audiencia Provincial el Procedimiento Abreviado no 2955/2012 procedente del Juzgado de Instrucción no 46 de Madrid, seguida de oficio por un delito de detención ilegal, suposición de parto y falsedad en documento oficial, contra el acusado [...]. (Sentencia núm. 640/2018 Audiencia Provincial de Madrid). 


\subsection{Ortográfico y estilo}

\subsubsection{Siglas-abreviaturas}

Las siglas son recurrentes en el lenguaje jurídico en aras de simplificar la denominación de instituciones (CEE por Comunidad Económica Europea), leyes (RD por Real Decreto), declaraciones (DUDH por Declaración universal de los Derechos Humanos) o códigos legislativos (CP por Código Penal) presentes en los textos. Las normas de redacción requieren la escritura extendida de la nomenclatura seguido de paréntesis con la sigla al menos durante su primera aparición.

Asimismo, se pueden encontrar numerosas abreviaturas recurrentes sobre todo en lo que Gualdo llama estilo «commatico» (2011, p. 448), es decir, en las partes en las que se puede dividir una ley: libro (lib.), título (tít.), capítulo (cap.), sección (secc.), artículo (art.), párrafo (pf.) y apartado (ap.).

Retóricamente las enumeraciones siempre han sido un punto a favor y la gran subdivisión que crean estos elementos en el texto otorgan al lenguaje jurídico una jerarquización precisa. Mortara Garavelli (2001) afirma que en las últimas décadas se han reducido los números de los artículos en favor de su subdivisión. Un claro ejemplo sería el art. 705 del Código penal italiano, el cual aparece reflejado en el libro III, título I, capítulo I, sección III y párrafo V. La gran precisión que otorga el lenguaje jurídico, lejos de buscar una lectura ágil, puede dificultar la tarea de la comprensión debido a los elevados giros intertextuales. Piénsese en las siguientes frases llenas de referencias intertextuales:



Cuando de acuerdo con lo establecido en el artículo 31 bis una persona jurídica sea responsable de los delitos comprendidos en los artículos 197, 197 bis y 197 ter, se le impondrá la pena de multa de seis meses a dos años. Atendidas las reglas establecidas en el artículo 66 bis, los jueces y tribunales podrán asimismo imponer las penas recogidas en las letras b) a g) del apartado 7 del artículo 33. (art. 197-quinquies) La condanna per i reati di cui agli articoli 314,317,319 e 319-ter importa l'interdizione perpetua dai pubblici uffici [...]. (art. 317-bis)

En ambos casos encontramos referencias intertextuales implícitas internas, pues no citan literalmente partes externas junto a los nuevos añadidos y mencionan partes internas de la ley en donde se encuadran. Un caso de referencia intertextualidad externa lo encontraríamos en el art. 1.4. de la Ley italiana medioambiental del 22 de mayo de 2015 núm. 68, la cual cita «[...] dopo la parola: "416-bis" sono inserite le seguenti: "452-quater, 452 octies, primo comma,"», haciendo referencia al Código penal italiano.

Es cuando menos interesante el adverbio latino que acompaña en los ejemplos italianos a estos artículos, el cual se usa para no deber modificar el número de artículos en la estructura de la ley original. Más concretamente, en español no se introduce el guion que separa el adverbio latín del número del artículo. Esta es una clara diferencia que podemos discernir en la redacción legislativa en ambos lenguajes, pues realizando una búsqueda del adverbio bis en el Código penal y civil de ambos idiomas encontramos que los 15 casos del CPI y los 15 casos del CCI llevan guion, mientras que en español los 31 casos del CP y los 7 casos del CC no.

\subsubsection{Oscurantismo}

En el lenguaje jurídico el oscurantismo representa una de las características que más acentúa la literatura de especialidad. A tal respecto, es interesante la reflexión histórica que aporta Fusco (2016), pues ya en el siglo 
XVII era recurrente el uso del latín para dificultar la comprensión del pueblo, lo cual contrasta con el papel relevante del destinatario final, ya que al eludir el carácter oscurantista de los textos, se propicia una mayor interpretación de los mismos (Breggia, 2013). La redacción ampulosa en ocasiones se convierte en falta de precisión al abrir las puertas a la voluntad subjetiva del sentenciador, pues esta ambigüedad en ocasiones se deja ver en el uso de adjetivos que utiliza el legislador y que empuja a concebir los hechos como atemporales. Encontramos dos ejemplos en la anterior ley medioambiental: «la cui eliminazione risulti particolarmente onerosa e conseguibile» (art. 452-quarter) y «chiunque abusivamente cagiona una compromissione o un deterioramento significativi e misurabili delle acque o dell'aria, [...]» (art. 452-bis). En ellos podemos observar la escasa concreción de los adjetivos en la definición de lo que se considera potencialmente gravoso en el primer ejemplo y peligroso en el segundo. No obstante, cabe destacar los esfuerzos que se están produciendo en ambos países en las últimas décadas a favor de una modernización del lenguaje jurídico para la mejora de la redacción legislativa, en donde encontramos con cierta recurrencia el Informe de la Comisión de modernización del lenguaje jurídico publicado en 2011 por el Ministerio de Justicia en 2011 y el Codice di stile delle comunicazioni scritte ad uso delle amministrazioni pubbliche publicado en 1993 por el Ministerio de Cassesse.

\section{Conclusiones}

El lenguaje jurídico es la expresión de la sociedad en la que se encuadra y en su cometido regula los comportamientos de la comunidad. La literatura de especialidad siempre ha puesto de manifiesto sus usos arcaizantes, repetitivos y su oscurantismo, dejando a un lado la gran flexibilidad que representa al absorber palabras provenientes de varios idiomas y de varios sectores y al usar formas verbales no tan usuales en la lengua común. En estas líneas hemos otorgado un breve análisis de las características del lenguaje jurídico en función de los planos que establece el análisis de textos. En el plano léxico-semántico, los anglicismos se muestran en italiano con gran predominio junto a los latinismos. Los arabismos son más frecuentes en español debido a ese periodo de reconquista que duró 7 siglos y en la fraseología jurídica, los binomios y multinomios están ampliamente aceptados en ambas lenguas, si bien los más comunes son los formados por sustantivos, verbos y adjetivos. En el plano morfosintáctico, la nominalización es un mecanismo muy utilizado al celar el sujeto. Sin embargo, el mayor protagonismo lo lidera la morfología verbal. En el lenguaje jurídico el italiano cuenta con un gran dominio del presente de indicativo, pues este se postula como el tiempo perfecto para expresar la percepción real que se tiene del hecho jurídico. No obstante, también tienen cabida en un segundo lugar y en menor proporción el futuro de indicativo y el subjuntivo, que gozan de un grado más elevado de probabilidad respecto al anterior y se sitúan como los predilectos para el caso español.

Por último, en el plano ortográfico y estilo, ambos idiomas dan muestras de una intertextualidad elevada en los textos jurídicos, probablemente debido al esfuerzo por parte del legislador de abarcar todas las casuísticas posibles, y de un oscurantismo no menos importante, pues la ambigüedad semántica representa un pilar fundamental en la conservación de las leyes, si bien abre las puertas a la peligrosidad que supone la libre interpretación de las mismas.

\section{Declaration of conflicting interests}

The author(s) declared no potential conflicts of interest with respect to the research, authorship, and/or publication of this article. 


\section{Funding}

The author(s) received no financial support for the research, authorship, and/or publication of this article.

\section{Sobre el autor}

Rubén González Vallejo recibe el Doctorado por la Universidad de Salamanca centrando sus investigaciones en la traducción jurídica y en la contrastiva lingüística entre el español y el italiano. Ello ha dado como fruto el volumen "Lenguaje jurídico comparado: análisis y traducción de los delitos medioambientales del Código penal italiano". Con una formación filológica y en traducción e interpretación, forma parte de diferentes grupos de investigación, centros de investigación y comités científicos. Actualmente enseña traducción e interpretación en la Universitá degli Studi di Macerata (Italia).

\section{Bibliografía}

Alcaraz, V., Hughes, B. (2002). El español jurídico. Barcelona: Ariel Derecho.

Belvedere, A. 2016. Scritti giuridici. Linguaggio e metodo giuridico. Milano: CEDAM.

Breggia, L. (2013). La semplificazione del linguaggio giuridico negli atti processuali. En A. Mariani e F. Bambi (Eds.), Lingua e diritto. Scritto e parlato nelle professioni legali (pp. 15-25), Pisa: Pisa University Press.

Caterina R. y Rossi, P. (2008). L’italiano giuridico. En B. Pozzo, Timoteo, M (Eds.), Europa e linguaggi giuridici (pp. 185-208). Milán: Giuffrè Editore.

Corbacho, A. (2004). Breve estudio sobre los germanismos del alemán en el lenguaje de la economía. Anuario de Estudios Filológicos, (27), 41-53. Recuperado de https://dialnet.unirioja.es/servlet/articulo?codigo=1078988

Corpas, G. (1998). Criterios generales de clasificación del universo fraseológico de las lenguas, con ejemplos tomados del español y del inglés. En Manuel Álvar y Gloria Corpas Pastor (Eds.), Diccionarios, frases, palabras (pp. 157-187). Málaga: Servicios de Publicaciones de la Universidad de Málaga.

Edelmann, G. (2012). El empleo del futuro de subjuntivo en la traducción de normas legales alemanas al español. En Pilar Martino Alba y Christiane Lebsanft (Eds.), Telar de traducción especializada (pp. 177-189). Madrid: Ed. Dykinson.

Frago, G. (1980). El helenismo culto en la documentación jurídica aragonesaun nuevo camino para la historia del léxico español. Archivo de filología aragonesa, 26-27, 393-400. Recuperado de https://ifc.dpz.es/recursos/publicaciones/06/68/06frago.pdf

Fusco, F. (2016). Il linguaggio del diritto e della burocrazia nel xix secolo tra aperture e istanze puristiche. LinguaDue, 1, pp. $246-268$.

González Vallejo, R. (2020). Lenguaje jurídico comparado: traducción y análisis de los delitos medioambientales del código penal italiano. Roma: Aracne.

Gotti, M. (1991). I linguaggi specialistici. Caratteristiche linguistiche e criteri pragmatici. Firenze: La Nuova Italia.

Gualdo, R. y Telve, S. (2011). Linguaggi specialistici dell'italiano. Roma: Carocci.

Lapesa, R. (1981). Historia de la lengua española. Madrid: Gredos.

Luciano, F. (2014). Redes de poder en el Sur de Italia en 1507. La sustitución de Gonzalo Fernández de Córdoba como virrey de Nápoles. Revista Chilena de Estudios Medievales, (6), 77.92. recuperado de http://revistas.ugm.cl/index.php/rcem/article/view/24/ 21

Malkiel, Y. (1959). Studies in irreversible binomials. Lingua, (8), 113-160. 
Mancini, M. (2010). Arabismi. En Enciclopedia dell'italiano Treccani. Roma: Istituto Enciclopedia Italiana. Recuperado el 14 de agosto de 2019 de http://www.treccani.it/enciclopedia/arabismi \%28Enciclopedia-dell\%27Italiano\%29/

Martínez, M. d. A. (1997). El verbo como elemento caracterizador. Anuario de Estudios Filológicos, 20, $253-258$.

Mortara Garavelli, B. (2001). Le parole e la giustizia. Divagazioni grammaticali e retoriche su testi giuridici italiani. Turín: Einaudi editore.

Millar, M. A. (1998). Los arabismos en la lengua española. Boletín de Filología, (37), 781- 801. Recuperado de https://boletinfilologia.uchile.cl/index.php/BDF/article/view/21486/22783

Nuñez, F. (2009). Diátesis pasiva en italiano y español. Apuntes para un análisis contrastivo. Language Design,(11), 79-92. Recuperado de http://elies.rediris.es/Language Design/LD11/LD11-04-Nunnez.pdf

Prieto, E. J. (1959). Parataxis e hipotaxis. Colección Ensayos y Estudios, Universidad Nacional del Litoral, Rosario.

Quiroga, P. 2006. Fraseología italo-española. Aspectos de lingüística aplicada y contrastiva. Granada: Granada lingüística.

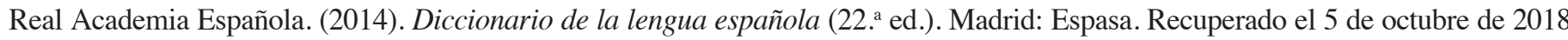
de http://www.rae.es/rae.html

Riccio, G. y Marinucci, M. (2005). Ispanismi nel dialetto napoletano. Trieste: EUT.

Rodríguez, B. (1981). Las lenguas especiales. El léxico del ciclismo. León: Colegio Universitario.

Sciutto, V. (2005). Unidades fraseológicas: un análisis contrastivo de los somatismos del español de Argentina y del italiano. AISPI. Actas XXIII, 502-518. Recuperado de https://cvc.cervantes.es/literatura/aispi/pdf/22/II 31.pdf

Vergara, L., Mansilla, A. (2017). Metáfora jurídica en la fraseología contrastiva en alemán y en español: el esquema de CAMINO. Alfinge, 29, 223-241.

Vučetic, Z. (2015). Il linguaggio della giurisprudenza dal punto di vista della formazione delle parole. Orientamenti e problemi lessicologici, Linguistica, (42), 65-80. Recuperado de https://revije.ff.uni-lj.si/linguistica/article/view/3955/3661

\section{Legislación}

Altalex. (s. f.). Codice civile. Recuperado de https://www.altalex.com/documents/codici-altalex/2015/01/02/codice-civile

Altalex. (s.f.). Codice Penal. Recuperado de https://www.altalex.com/documents/codici-altalex/2014/10/30/codice-penale

Anuncio de formalización de contratos. BOE núm. 78.

Código Civil. Gaceta de Madrid. núm. 206, de 25 de julio de 1889. Recuperado de https://www.boe.es/buscar/pdf/1889/BOE-A-18894763-consolidado.pdf

Código Penal. BOE núm. 281, de 24 de noviembre de 1995. Recuperado de https://www.boe.es/buscar/pdf/1995/BOE-A-1995-25444consolidado.pdf

Decreto Legislativo 12 de septiembre de 2018 núm. 116. Gazzetta Ufficiale núm. 235.

Decreto Legislativo 15 de diciembre de 2017, núm. 223. Gazzetta Ufficiale núm. 14.

Decreto Legislativo 19 de febrero de 2019 núm. 17. Gazzetta Ufficiale núm. 59.

Decreto Legislativo 3 de noviembre de 2003, n. 307. Gazzetta Ufficiale núm. 266.

Decreto Legislativo de 29 de mayo de 2017 núm. 94 . Gazzetta Ufficiale núm. 143.

Decreto Ley de 25 de noviembre de 2019 n. 165. Gazzetta Ufficiale núm. 6.

Decreto Ley de 27 de abril de 2018 núm. 38. Gazzetta Ufficiale núm. 97.

DPCM 6 de noviembre de 2019 núm. 138. Gazzetta Ufficiale núm. 282.

Ley 2 de julio de 2020, núm. 72. Gazzetta Ufficiale núm. 171.

Ley 11/2019 de 20 de diciembre. BOE núm. 14. 
Ley 15 de julio de 2009, n. 94. Gazzetta Ufficiale n. 170.

Ley 17 de diciembre 1997, núm. 433. Gazzetta Ufficiale núm. 295.

Ley 2 de abril de 2015 núm. 44. Gazzetta ufficiale núm. 92.

Ley 4/2020 de 29 de abril de 2020. BOE núm. 155.

Ley 6/2019 de 23 de diciembre. BOE núm. 33.

Ley de 22 de mayo de 2015 núm. 68. Gazzetta Ufficiale n. 122.

Ley Orgánica 1/2015 de 30 de marzo. BOE, núm. 77.

Ley Orgánica 4/2000 de 11 de enero. BOE núm. 10.

Ley Orgánica 7/1981 de 30 de diciembre. BOE núm. 9.

Real Decreto 463/2020, de 14 de marzo. BOE núm. 67.

Real Decreto 647/2020 de 7 de julio. BOE núm. 187.

Reglamento CE núm. 2698/2000 de 27 de noviembre de 2000. DOCE núm. 311.

Resolución 19 de octubre de 1982. BOE núm. 266.

Resolución de 6 de marzo de 2020. BOE núm. 185.

Sentencia núm. 640/2018 Audiencia Provincial de Madrid. PA 544/2017 